Nanomanufacturing and Metrology (2018) 1:248-251

\title{
Reinforcement of TiB2 Nanoparticles in Aluminium Piston Alloys for High \\ Performance at Elevated Temperature
}

Yijie Zhang 1, Sajjad Amirkhanlou 2, Shouxun Ji 1

(shouxun.ji@brunel.ac.uk)

1 Institute of Materials and Manufacturing, Brunel University London, Uxbridge, Middlesex UB8 3PH, UK

2 Department of Materials, University of Oxford, Parks Road, Oxford OX1 3PH, UK

\begin{abstract}
Nano-TiB2 particles produced by in situ approaches were employed to reinforce the Mahle 174 piston alloy. Experimental results showed that, with TiB2 nanoparticles, the mechanical properties were significantly improved at ambient and elevated temperatures. The ultimate tensile property at room temperature was increased from 250 to $332 \mathrm{MPa}$. The ultimate tensile property at $300{ }^{\circ} \mathrm{C}$ was increased from 121 to $174 \mathrm{MPa}$, and that at $350{ }^{\circ} \mathrm{C}$ was increased from 86 to $116 \mathrm{MPa}$. The increase was $82 \mathrm{MPa}$ at ambient temperature, $53 \mathrm{MPa}$ at $300{ }^{\circ} \mathrm{C}$ and $30 \mathrm{MPa}$ at $350{ }^{\circ} \mathrm{C}$, respectively. The mechanism of property improvement in the nanocomposites is attributed to the well-distributed nanoparticles in $\mathrm{Al}$ matrix, thermal stability of TiB2 at high temperature and the formation of high density of dislocation network in the vicinity of $\mathrm{TiB} 2 / \mathrm{Al}$ interface.
\end{abstract}

\section{Keywords}

Nanocomposites $\cdot$ Piston alloy $\cdot$ Microstructure $\cdot$ Mechanical property $\cdot$ High-temperature properties

\section{Introduction}

Piston components produced by $\mathrm{Al}$ alloys have been extensively achieved in industry to obtain light weighting in transport manufacturing. The increasingly restricted demands of low emission of internal combustion engines require a high explosion pressure and working temperature in the cylinder chambers, which results in the increase in service temperature and mechanical properties of piston up to $400{ }^{\circ} \mathrm{C}$. Therefore, piston alloys with high strength above $300{ }^{\circ} \mathrm{C}$ are attracting more and more attention. In general, the strengthening at elevated temperature mainly results from grain boundary strengthening, precipitation strengthening and secondary phase strengthening. The elements such as $\mathrm{Si}, \mathrm{Fe}, \mathrm{Cu}$ and $\mathrm{Ni}$ form intermetallic and eutectic phases along grain boundaries to contribute the grain boundary strengthening and secondary phase strengthening. The elements such as $\mathrm{Mg}, \mathrm{Cu}, \mathrm{V}$ and $\mathrm{Zr}$ can form very fine precipitates in the $\mathrm{Al}$ matrix for precipitation strengthening [1]. In the 
currently used pistons, $\mathrm{Al}-\mathrm{Si}$ alloys are popular due to their good castability and acceptable durability and machinability, in which the $\mathrm{Mg}$ and $\mathrm{Cu}$ are the best and economic elements employed to enhance the anti-deformation capability of Al piston alloys. The Mg2Si and $\mathrm{Al} 2 \mathrm{Cu}$ are two key phases formed as secondary phases in grain boundaries and as precipitates within $\alpha$-Al matrix for strengthening. The Mg2Si can improve the high-temperature property up to $180^{\circ} \mathrm{C}$, and $\mathrm{Al} 2 \mathrm{Cu}$ can improve the high-temperature property up to $300{ }^{\circ} \mathrm{C}$. Above the critical temperature, these phases will become unstable and grow quickly with prolonged time at high temperature and subsequently lose their strengthening advantages in the piston alloys.

To further improve the mechanical properties of $\mathrm{Al}$ piston alloys at high temperature, it is necessary to reinforce the alloy by fine precipitates that are stable and no obviously growth at high temperature. Particle-reinforced metal matrix composites (MMCs) are the capable materials and good candidates to provide good mechanical properties above $300{ }^{\circ} \mathrm{C}$ because of the existence of ceramic particles in the matrix, such as SiC, AlN and TiB2.

It was reported that the creep resistance of the $\mathrm{Al}$ composites increases with increasing volume fraction of $\mathrm{SiC}$ reinforcement [2, 3]. The experimental results of Ma et al. revealed that the $\mathrm{Al}$ composite containing AlN particles has excellent ultimate tensile strength at both the room temperature and the high temperature of $350{ }^{\circ} \mathrm{C}$ [4]. The $\mathrm{Al}$ composites reinforced by TiB2 particles possessed the good ultimate tensile strength at high temperature between 300 and $400{ }^{\circ} \mathrm{C}[5,6]$. However, in the as-cast microstructure, most of the ceramic particles formed by in situ or ex situ approaches are located in the grain boundary after solidification, showing the significant non-uniform distribution and therefore not beneficial for the mechanical properties. Consequently, the challenge is how to obtain the well-distributed particles in the $\mathrm{Al}$ matrix, of which the refinement of primary aluminium phase is an effective way. Nano-TiB2 particles have been proved to be able to act as nucleation sites during solidification to effectively refine the grain size of primary Al phase [7-9]. In reality, the addition of $0.2 \mathrm{wt} \%$ Al5Ti1B master alloy into aluminium alloys as grain refiner is a common practice in casting manufacturing [10], by which only $0.0064 \mathrm{wt} \% \mathrm{TiB} 2$ particles are introduced into $\mathrm{Al}$ melt. The amount of TiB2 particle is significantly insufficient as the reinforcement phase for the strengthening at high temperature.

Therefore, in the present study, we tried to investigate the influence of nano-TiB2 particles on the mechanical properties of the Mahle 174 piston alloy at different temperatures. About 5 wt\% nano-TiB2 particles were produced by in situ technology in the Mahle 174 piston alloy as reinforcement phases for high temperature. The mechanisms of the property improvement in the nanocomposites are discussed in association with the relationship between the nanoprocessing, microstructure and mechanical properties.

\section{Experimental}

Mahle 174 alloy (11\%Si, 3.5\%Cu, 2\%Ni, 0.6\%Mg, 0.15\%Zr, $0.15 \% \mathrm{~V}$ and $0.15 \% \mathrm{Ti})$ was employed as matrix alloy to produce nano-TiB2-reinforced composite. In situ technology of 
chemical reactions between $\mathrm{K} 2 \mathrm{TiF} 6, \mathrm{KBF} 4$ and $\mathrm{Al}$ at $850{ }^{\circ} \mathrm{C}$ for $1 \mathrm{~h}$ was used to prepare TiB2 particles. In the liquid state of $\mathrm{K} 2 \mathrm{TiF} 6, \mathrm{KBF} 4$ and $\mathrm{Al}$ at $850{ }^{\circ} \mathrm{C}$, three reactions occurred to synthesize TiB2 particle. [Ti] was extracted from the reaction between K2TiF6 and $\mathrm{Al}$, and [B] was extracted from the reaction between KBF4 and Al. Then, [Ti] and [B] were combined together to form TiB2 particles. After the completion of the reaction process, the rotary degassing was used to purify the melt and then the melt was poured into the tensile sample mould designed according to ASTM-557 standard. All samples were subjected to the T6 heat treatment, in which the samples were solutionized at $515{ }^{\circ} \mathrm{C}$ for $2 \mathrm{~h}$ and immediately quenched into the water at ambient temperature; after 24-h stabilization at room temperature, the samples were aged at $170{ }^{\circ} \mathrm{C}$ for $10 \mathrm{~h}$. The tensile properties were tested using an Instron 5500 testing machine at different temperatures. The ramp rate was $1 \mathrm{~mm} / \mathrm{min}$. For hightemperature testing, the samples were held for $30 \mathrm{~min}$ to homogenize the sample temperature at the given temperature before testing. Samples for microstructure analysis were prepared following the standard procedure. Scanning electron microscopy (SEM) and transmission electron microscopy (TEM) were employed to observe the microstructure.

\section{Results and Discussion}

Figure 1 shows the ultimate tensile properties (UTS) of the Mahle 174 matrix alloy and the TiB2- reinforced composite with Mahle 174 alloy (TiB2/Mahle 174). It can be seen that in situ nano-TiB2 particles can improve the properties significantly at both the room temperature and the high temperatures. The UTS of Mahle 174 alloy was $250 \mathrm{MPa}, 121 \mathrm{MPa}$ and $86 \mathrm{MPa}$ and that of TiB2/ Mahle 174 composite was $332 \mathrm{MPa}, 172 \mathrm{MPa}$ and $116 \mathrm{MPa}$, respectively, at ambient temperature $\left(25^{\circ} \mathrm{C}\right), 300^{\circ} \mathrm{C}$ and $350^{\circ} \mathrm{C}$. The increase in UTS was $82 \mathrm{MPa}$ at $25^{\circ} \mathrm{C}, 51 \mathrm{MPa}$ at $300{ }^{\circ} \mathrm{C}$ and $30 \mathrm{MPa}$ at $350{ }^{\circ} \mathrm{C}$, respectively.

Grain refinement has been recognized as an effective strengthening approach in $\mathrm{Al}$ alloys [11, 12]. In the experimental alloys, the grain size of the as-cast microstructure had the same level in these two alloys. Therefore, the grain refinement strengthening did not contribute to the improvement of mechanical properties. Precipitation strengthening is mainly influenced by the morphology and the size of the precipitates formed during heat treatment which is determined by the alloy composition and heat treatment process. In the present study, the same condition in the alloy composition, casting process and heat treatment of Mahle 174 and TiB2/ Mahle 174 indicated that there was no obvious difference of the contribution of the precipitation strengthening on the improvement of the Fig. 1 Comparison of ultimate tensile strengths of Mahle 174 alloy and nano-TiB2-reinforced Mahle 174 composite at room temperature, $300{ }^{\circ} \mathrm{C}$ and $350{ }^{\circ} \mathrm{C}$ UTS. For the $\mathrm{Al}$ composites reinforced by nanoparticles, the high density of dislocation network could be formed in the vicinity of the interface between the reinforcement and the matrix. These dislocations could be generated by the high thermal stress during solidification and heat treatment process because of the difference of the coefficient of thermal expansion between the nanoparticles and the base alloy. The particles with fine sizes and uniform distribution in the matrix are favourite to Orowan strengthening caused by the dislocation movement during deformation. Figure 2 shows a representative 
micrograph of the TiB2 particle sizes and morphologies in TiB2/Mahle 174 composite. It can be seen that the morphology of TiB2 particles was the typical hexagonal and cubic with the size between 10 and $100 \mathrm{~nm}$. More importantly, these particles were well distributed in matrix, which could effectively uniform the stress concentration and enhance the mechanical properties. It should be emphasized that the TiB2 particles have a high elastic modulus of 560 GPa and are in nanosizes in the composite. The dislocation movement will form Orowan loops around the particles rather than cut through them as dislocation gliding.

The more interaction between dislocation loops, the more resistance on the dislocation movement. This will directly result in the increase in strength in the nano-TiB2-reinforced Al composite. On the other hand, the detrimental effect by the agglomeration of TiB2 particles could be minimized in the nanocomposites synthesized by in situ method. For particlesreinforced $\mathrm{Al}$ composites, the interface between the reinforcement phase and the matrix plays an important role in the enhancement of mechanical properties. The good bonding will benefit the property improvement, whilst the bad bonding should minimize or avoid through the control of synthesis process. The common defects on the interface between particle and matrix are non-bonding and/ or the existence of the brittle secondary phases.

Figure 3 reveals a typical interface between the TiB2 particle and the Al matrix in the experimental TiB2/ Mahle 174 composite. Figure 3a shows that the interface between TiB2 and $\mathrm{Al}$ matrix was very clean and no defect was found over there. It is further proved by Fig. $3 \mathrm{~b}$ that no reaction layer and no any brittle phase were detected on the TiB2/Al interface. This was another proof of the TiB2 particles acting as reinforcement phases other than as inclusions having an adverse effect performance [13]. Proper interface is critical to achieve the property improvement at high temperature via contributions from both the secondary phase strengthening and the precipitation strengthening.

\section{Conclusions}

The property improvement of piston alloys at high temperature can be achieved by employing nano-TiB2 particles as reinforcements to produce Mahle 174 composite. The ultimate tensile strength at room temperature was increased from 250 to $332 \mathrm{MPa}$. The ultimate tensile strength at $300{ }^{\circ} \mathrm{C}$ was increased from 121 to $174 \mathrm{MPa}$, and that at $350{ }^{\circ} \mathrm{C}$ was Fig. 2 Size, morphology and distribution of in situ TiB2 particles in Mahle 174 composite Fig. 3 a Bright-field TEM image of TiB2 particle and $b$ the high-resolution TEM image of TiB2/ Al interface increased from 86 to $116 \mathrm{MPa}$. The improvement was attributed to the well-distributed particles in $\mathrm{Al}$ matrix and the dislocation strengthening caused by nanoparticles.

\section{References}

1. Dong X, Zhang Y, Amirkhanlou S, Ji S (2018) High performance gravity cast Al9Si0.45Mg0.4Cu alloy inoculated with AlB2 and TiB2. J Mater Process Tech 252:604-611 
2. Tjong SC, Ma ZY (1997) The high temperature creep behaviour of aluminium-matrix composites reinforced with SiC, Al2O3 and TiB2 particles. Compos Sci Tech 57(6):697-702

3. Ryu HJ, Chung KH, Cha SI, Hong SH (2004) Analysis of creep behavior of SiC/Al metal matrix composites based on a generalized shear-lag model. J Mater Res 19(12):3633-3640

4. Ma X, Zhao YF, Tian WJ, Qian Z, Chen HW, Wu YY, Liu XF (2016) A novel Al matrix composite reinforced by nano-AlNp network. Sci Rep 6:34919

5. Yi H, Ma N, Li X, Zhang Y, Wang H (2006) High-temperature mechanics properties of in situ TiB2p reinforced Al-Si alloy composites. Mater Sci Eng A 419(1):12-17

6. Onoro J (2011) High-temperature mechanical properties of aluminium alloys reinforced with titanium diboride (TiB2) particles. Rare Met 30(2):200-205

7. Easton M, StJohn D (2001) A model of grain refinement incorporating alloy constitution and potency of heterogeneous nucleant particles. Acta Mater 49(10):1867-1878

8. Fan Z, Wang Y, Zhang Y, Qin T, Zhou XR, Thompson GE, Pennycook T, Hashimoto T (2015) Grain refining mechanism in the Al/Al-Ti-B system. Acta Mater 84:292-304

9. Zhang Y, Ma N, Yi H, Li S, Wang H (2006) Effect of Fe on grain refinement of commercial purity aluminum. Mater Des 27(9):794-798

10. Zhang Y, Ma N, Wang H, Li X (2008) Study on damping behaviour of A356 alloy after grain refinement. Mater Des 29(3):706-708

11. Zhang Y, Ji S, Fan Z (2017) Improvement of mechanical properties of Al-Si alloy with effective grain refinement by in situ integrated Al2.2Ti1B-Mg refiner. J Alloys Compd 710:166-171

12. Zhang Y, Ma N, Le Y, Li S, Wang H (2005) Mechanical properties and damping capacity after grain refinement in A356 alloy. Mater Lett 59:2174-2177

13. Amirkhanlou S, Ji S, Zhang Y, Watson D, Fan Z (2017) High modulus Al-Si-Mg$\mathrm{Cu} / \mathrm{Mg} 2 \mathrm{Si}-\mathrm{TiB} 2$ hybrid nanocomposite: microstructural characteristics and micromechanicsbased analysis. J Alloys Compd 694(15):313-324 


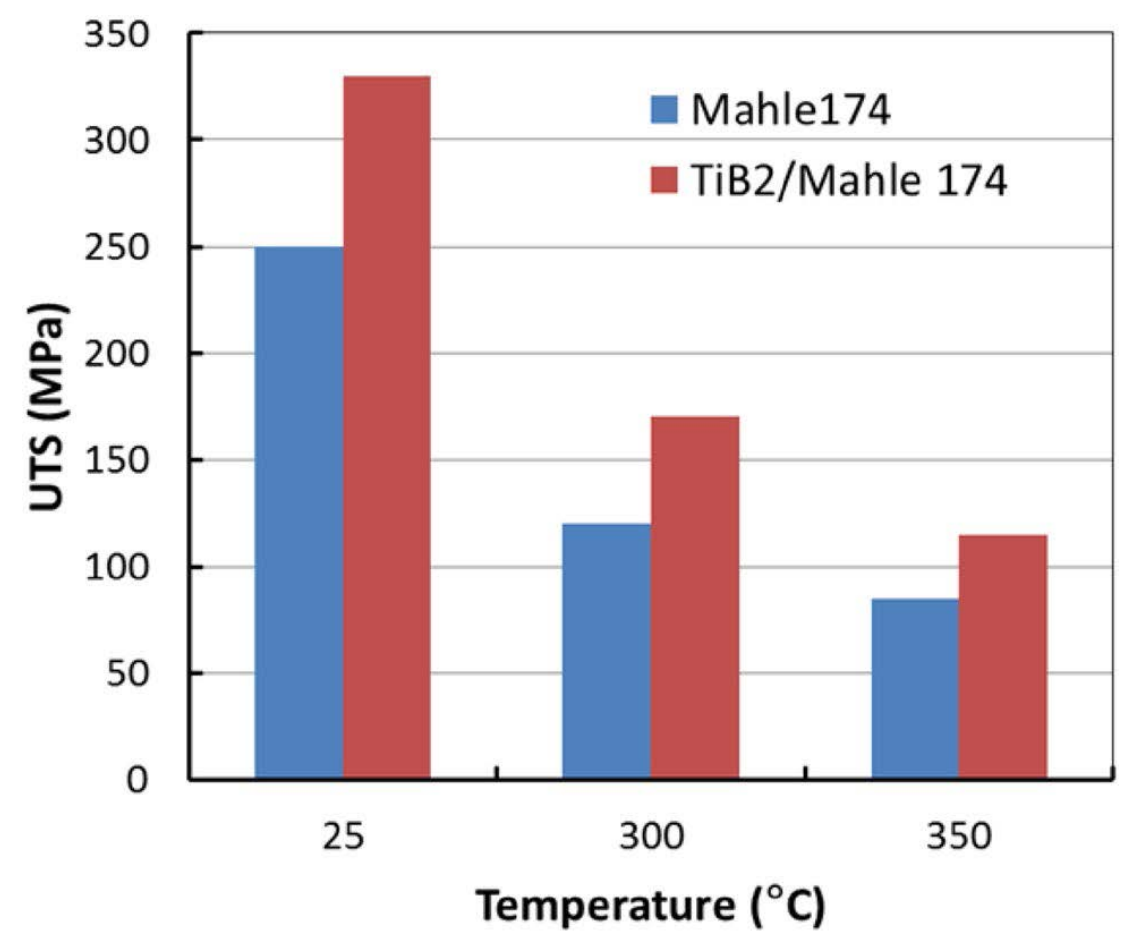

Fig. 1 Comparison of ultimate tensile strengths of Mahle 174 alloy and nano-TiB2-reinforced Mahle 174 composite at room temperature, $300^{\circ} \mathrm{C}$ and $350{ }^{\circ} \mathrm{C}$

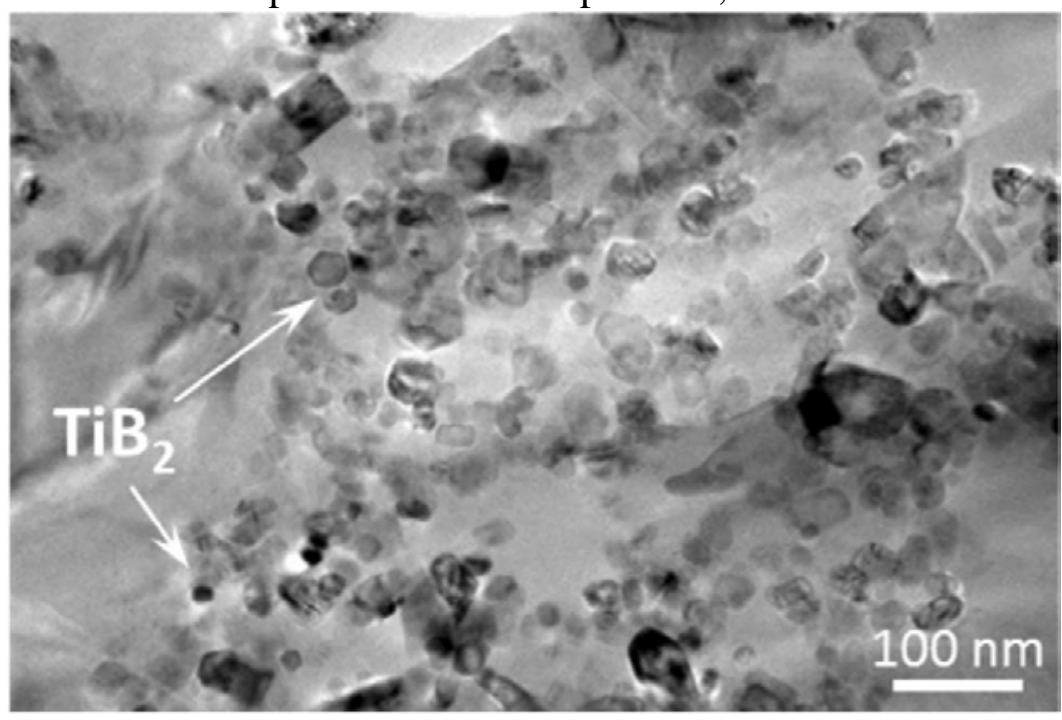

Fig. 2 Size, morphology and distribution of in situ TiB2 particles in Mahle 174 composite 

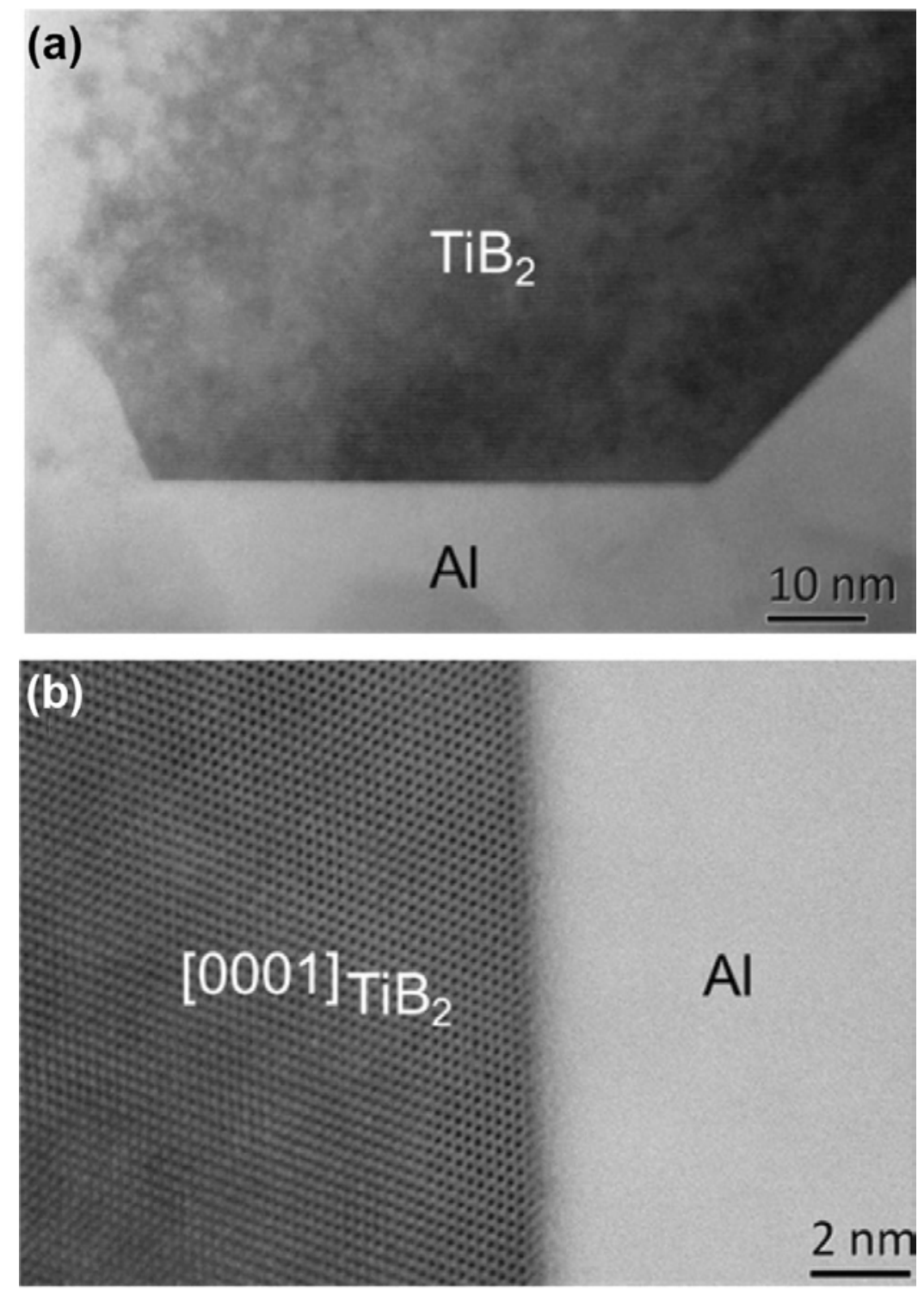

Fig. 3 a Bright-field TEM image of TiB2 particle and $\mathbf{b}$ the high-resolution TEM image of TiB2/ Al interface 